\title{
Role of plant growth promoting rhizobacteria as ameliorating agent in saline soil
}

\author{
Nazima Batool ${ }^{1}{ }^{1}$ Noshin Ilyas ${ }^{1}$ and Armghan Shahzad ${ }^{2}$ \\ ${ }^{1}$ Depertment of Botany, Pir Mehr Ali Shah Arid Agriculture University, Rawalpindi 46000, Pakistan \\ ${ }^{2}$ National Institute for Genomics and Advanced Biotechnology, (NARC), Islamabad, Pakistan. \\ *Corresponding author email: nazimabatool@ gmail.com Phone number: 009203062263354
}

Citation

Nazima Batool, Noshin Ilyas and Armghan Shahzad. Role of plant growth promoting Rhizobacteria as Ameliorating agent in saline soil. Pure and Applied Biology. Vol. 3, Issue 4, 2014, pp 167-174

\begin{abstract}
Abiotic stress factors severely affect the crop plant growth, yield and productivity in the semiarid areas. Though, salt stress is one of the important reasons to reduce crop growth and productivity. High salt in soil is reason to produce critical conditions for plant survival. A number of scientists focus their research to identify tolerance mechanisms in plants under saline soil, although utilization of this information limited to improve crops. In recent years, number of scientist identified tolerance mechanism induced by Plant Growth Promoting Rhizobacteria (PGPR) in crop plants under saline conditions. PGPR Identification and exploitation is proving to be new alternatives against salt stress. Although, PGPRs mechanism of action is not understood. PGPRs application increases water and nutrient uptake and improve phytohormone production. The main aim in this review is to illustrate role of PGPRs as ameliorating agent in crop plant under saline soil.
\end{abstract}

Keyword: PGPR; saline soil; plant survival

\section{Introduction}

Cultivated soils throughout the world sever affected from marginal irrigation desertification processes and excessive water. Salt stress is a rigorous dilemma in tropical, arid and temperate agriculture system [1]. In current years about 800 million ha of land is affected due to salt worldwide [2] and in Pakistan about 6 million ha area [3]. Pakistan is located in arid and semiarid region. In this region high evaptranspiration that causes deposition of salts on the soil surface. Saline condition is main factors which limit food production as a result; it decreases crop plants productivity [4-6]. High salt concentration may exacerbate other stress factors such as oxidative stress and protein denaturation in plants. Plant adapted a number of strategies to overcome harmful impacts of salinity by developing salt resistant varieties, leaching excess soluble salts from upper to lower soil depths and salt accumulation by aerial plant parts [7].

High salt concentration interferes with plant growth because it causes osmotic stress, toxic ion accumulation and nutrient 
imbalance. Salt stress may be due to high levels of $\mathrm{Na}+, \mathrm{K}+, \mathrm{Mg}+$, or $\mathrm{Ca} 2+$ of salt; however $\mathrm{NaCl}$ is the major reason $[5,6,8]$. When salt stress condition prevails for a long time it may induce in plants accumulation of osmolytes, stress protein production and reactive oxygen species scavenging systems. In recent years, the number of scientists tries to enhance plant tolerance in the salt stress situation. Plant tolerance either through chemical treatments such as plant hormones, minerals, amino acids, quaternary ammonium compounds, polyamines, vitamins, biofertilizers treatments; Asymbiotic nitrogen fixing bacteria, symbiotic nitrogen fixing bacteria, mycorrhiza and enhanced tolerance by using genetic modification [9].

Plant growth promoting bacteria (PGPB) are inoculated in seed and seedlings of crop plant this helps to alleviate salt stress effect. Crop production decrease as a result of the severity of abiotic stresses, particularly high salt condition, so tolerance mechanism to stress provided by PGPB inoculants becomes more significant. Rhizosphere is soil surrounded directly from the root system, whereas bacteria colonizing in the root environment are referred as rhizobacteria. PGPB in saline condition related to hydraulic conductance, compatible solute addition, confiscate toxic sodium ions and higher stomatal conductance. In saline environments PGPRs may increase plant growth and development by direct and indirect mechanisms. Plant hormones such as auxin, cytokinin and gibberelin produce by promoting bacteria indirect mechanism
[10]. PGPRs can also stop the harmful effects of one or more phytopathogenic organisms and stresses from the environment [11]. ACC deaminase activities in PGPRs have been used to decrease the harmful effects of salt stress because PGPRs slow down ethylene production in plant roots [1]. Bacteria isolated with PGP activities from physically salt affected help to ameliorate the harmful effect on wheat plants [12]. Numerous genera such as Pseudomonas, Bacillus, Arthrobacter, Azospirillum, Klebsiella, Enterobacter, Azotobacter, Herbaspirillum, Burkholderia, Rhizobium, Gluconacetobacter, Alcaligenes, and Serratia have been isolated from the rhizosphere of different crops [13, 10]. These bacterial strains have the ability to produce non enzymatic antioxidants [14]. Exopolysaccharides produce by bacterial strains help to bind cations such as calcium, potassium and sodium. Approximately fifty percent organic forms of phosphorus are synthesized by plants and microorganisms in the soil. In recent studies six phosphobacteria strains were identified from the rhizosphere of Lolium perenne, Trifolium repens, Triticum aestivum, Avena sativa and Lupinus luteres [15]. PGPRs can avoid the detrimental effects of stress factor from the environment. Besides this, the beneficial and suitable PGPRs identification, selection and application can increase the options to compete with increasing harmful effects of abiotic factor. In this review, we discuss plant growth promoting bacteria role in saline soil. 
Fig.1. Illurtation of PGPRs role in salt stress harmful effects alleviation.

\section{Plant Growth Promoting Rhizobacteria role in water homeostasis:}

The salinity negative effect is to disturb water uptake and reduce plant yield, so water homeostasis is essential. As salt stress has induced changes in turgor potential of plant cells if PGPRs plant shows osmotic adjustment to salt stress [16]. PGPRs can affect root hydraulic conductance of Phaseolus vulgaris plants under salt stress than un-inoculated plants $[17,18]$. Likewise, Zea mays plant's roots were inoculated with Bacillus megaterium in high salt levels as result plant able to sustain with stress condition [19, 20]. In stressed plant proline synthesis increases due to application of Burkholderia, Arthrobacter and Bacillus [21]. Though proline synthesizes mechanism is not clear, on the other hand proBA gene derived from Bacillus subtilis and introduces into Arabidopsis thaliana as a result of this induction increased proline production [22, 23, 24]. In an experiment 7200 expressed sequence tags from plants inoculated with strains over expressing the trehalose-6- phosphate synthase gene revealed upregulation of genes involved in stress tolerance [25]. Glomus fasciculatum colonize crop plant roots as a result increased soluble sugar production. Though, carbohydrate accumulation should be also considered in relation to its production in source leaves and its transport and use in actively growing sink tissues. This has an important implication for biomass reallocation, plant adaptation, photosynthesis, and growth [26].

\section{Plant Growth Promoting Rhizobacteria Role in Ion Balance:}

A number of metabolic and physiological changes in plants under salt stress related to plant tolerance and mostly ion exclusion from the leaves, thus ions toxic effects are avoided or delayed [5]. PGPRs role in maintaining toxic ion concentration in Plant growth under salt stress it must be beneficial. Sodium and chloride accumulation decrease due to PGPRs ion transporter expression that can adjust toxic ion uptake and alter rhizosheaths produced by bacterial exopolysaccharides. 
Rhizosphere $\mathrm{pH}$ changes are caused by microbes increase the availability of macro and micronutrients to plant [27]. Sodium accumulation decreased due to Glomus intraradices in Lotus glaber root and shoot [28]. Glomus clarumand improve growth and development of Vigna radiata plant in salinity. Correspondingly, other scientist's findings also show that PGPRs increase growth, development and yield in crop plants [29]. Recent results show that PGPRs can increase uptake of potassium, magnesium and calcium and decrease sodium uptake. PGPRs this role helps to maintain internal potassium and sodium levels. Uptake of toxic ions could more or less lessen harmful effects of salinity on crop plants [30].

Sodium accumulation decreased by bacterial exopolysaccharides because PGPRs bind with sodium ion in the roots therefore avoids transfer to leaves and stem of plant [31]. Besides, PGPRs with 1-aminocyclopropane1-carboxylic acid (ACC) deaminase enhance absorption of nitrogen, phosphours and potassium in Zea mays [32] and Phosphours, potassium and calcium accumulation increased in tomato plant under salt stress condition [1]. Microbes not only delay uptake of sodium but also promote sodium extrusion from the shoot [32]. High affinity potassium ion transporter differentially regulated sodium and potmassium levels depending on the plant species and plant tissue. Number of scientists observes that the induction of AtHKT1 decreased sodium accumulation and improved tolerance mechanism. Salt stress phenotype and inhibited growth observed when exposing an AtHKT1 mutant to bacterial volatile organic compounds [33]. Nonetheless, [34] findings demonstrate that PGPR in salt stress play an important role in the alleviation of osmotic stress effects by maintaining higher stomatal conductance and photosynthetic activities [26].

\section{Plant Growth Promoting Rhizobacteria Role in Phytoharmone Production}

In the rhizosphere microbial community present has been identified and recognized in auxin synthesis. In recent year's research, scientist discovered $80 \%$ microorganisms hold the ability to synthesize and release auxins. Plant auxin level variations due to PGPRs auxin level in soil, but sometime auxin produced by rhizobacteria that delay various plant developmental processes [35, 36]. Auxin play important role in plant growth as well as in plant defense system. [37] explain auxin synthesis, transport and signaling mechanism with auxin function. Indole aceic acid (IAA) play important role in seed germination, root cells growth and development and adventitious root formation. IAA3 directs shoot growth towards light, root growth under gravity, regulates chlorophyll synthesis, enhance photosynthesis and help plant withstand stress condition. PGPRs auxin enhances root formation, root area and root hairs and gives the plant roots large area to absorb maximum nutrients. [36] describe rhizobacterial auxin slacken plant cell walls facilitates an increasing amount of root exudation that provides additional nutrients to support the growth of rhizosphere bacteria. Therefore, Spaepen and Vanderleyden [35] recognized auxin as the key molecule in plant microbe interaction.

Tryptophans regulate auxin synthesis and tryptophans play important role to change the level of endogenous auxin [38]. Tryptophan stops anthranilate formation by a negative feedback mechanism because anthranilate decrease IAA synthesis, although anthranilate act as precursor for tryptophan biosynthesis [39]. Nevertheless, [35] findings suggest that in rhizobacteria culture if media supply with the tryptophan, 
PGPRs auxin production increases. [35] describe that five different pathways for the synthesis of auxin and (1) explain auxin production through IAA3 and IAA3 aldehyde is found in Erwinia herbicola, Agrobacterium,

Pseudomonas, Bradyrhizobium, Rhizobium, Azospirillum, Klebsiella, and Enterobacter. (2) In Pseudomonads and Azospirilla tryptophan conversion into IAA3 aldehyde another pathway in which tryptamine formed (3) indole 3 acetamide responsible for auxin formation in Agrobacterium tumefaciens, Pseudomonas syringae, Pseudomonads putida and pseudomonads fluorescens. (4) in the Synechocysti ssp. tryptophan conversion into indole-3-acetonitrile (5) the tryptophan pathway found in azospirilla and cyanobacteria similar to plants [40].

In salt stress plants root and stem xylem sap show increase in abscisic acid (ABA) levels [41]. [42] explain that in vitro ABA production mediate by many PGPRs. Even though numerous plant growth promoting rhizobacteria (PGPRs) isolated and recognized from weed species. Weed spp mostly grown in saline soil and them able to produce ABA in vitro. So, PGPRs may enhance growth of soybean seedlings under saline soil [43]. Gossypium hirsutum seeds dipped in suspensions of Pseudomonas putida for $6 \mathrm{~h}$ before planting. This practice may increase seedling biomass accumulation about $10 \%$ in saline soil [44]. Lettuce plants grow in dry soil with PGPR Bacillus subtilis producing significant root to shoot cytokinin signaling [45]. [46] demonstrate that cytokinin production appeared to the relatively common trait of PGPR and mycorrhizal fungi [42].

Phosphorus is present in the soil as an inorganic mineral, but sometime deficiency of phosphorus in soils overcomes by regular applications of phosphate fertilizers in the fields. However, [46] explain that plants able to absorb low concentration of applied phosphate fertilizers, but most of rapidly converted into insoluble complexes. Phosphate fertilizers regular application is costly and environmentally hazardous. This has led to search for an ecologically safe and economically reasonable option for improving crop production in low $\mathrm{P}$ soils. PSM (phosphate solubilizing microorganisms), have ability solubilize $\mathrm{P}$ to accessible forms of plants, so PSM provides a possible alternate to chemical phosphate fertilizers [47]. Phosphate solubilizing bacteria (PSB) are considered as promising biofertilizers since they can supply plants with $\mathrm{P}$ from insoluble sources [48]. [40] reported Azotobacter, Bacillus, Beijerinckia, Burkholderia, Enterobacter, Erwinia, Flavobacterium, Microbacterium, Pseudomonas, Rhizobium and Serratiaare mainly important phosphate solubilizing bacteria. In some bacterial strain phosphate solubilization and mineralization can coexist [49]. Nevertheless, phosphates solubilizing bacterial strains are normally found play an important role in their establishment and enhance phosphate performances are severely affected by environmental factors, especially under stress conditions [50].

\section{Plant Growth Promoting Rhizobacteria Role in Metabolite Transport:}

[26] results explain that Glomus mosseae colonized roots of Zea mays plant and they accumulate soluble sugars. In stress conditions, plants start to produce osmolytes and they help to enhance the plant water uptake, increase chlorophyll synthesis and photosynthetic ability. Capsicum annuum plant shows higher dry matter accumulation when roots inoculated with the Azospirillum brasilense and Pantoea dispersa. Plants with PGPRs inoculation maintain higher source activity due to increased stomatal conductance and photosynthesis than plants without PGPRs [34]. 


\section{Conclusions.}

In saline conditions PGPRs can induce tolerance mechanism in crop plants PGPRs able to promote plant growth and development. In recent year's number of scientists explains plant microbe interactions help to develop tolerance mechanisms in saline soil, but still need to understand in detail their molecular and biochemical mechanism. On the other hand, PGPRs not play an important role to tolerate stress condition, but they also improve soil fertility.

\section{References.}

1. Mayak S, Tirosh T, \& Glick BR (2004). Plant growth-promoting bacteria confer resistance in tomato plants to salt stress. Plant Physiology and Biochem. 42: 565572.

2. Munns R (2005). Genes and salt tolerance: bringing them together. New Phytol. 167: 645-663.

3. Chatrath R, Mishra B, Ortiz Ferrara G, Singh SK \& Joshi AK (2007). Challenges to wheat production in South Asia. Euphytica. 157: 447-456.

4. Evans AEV, Hanjra MA, Jiang Y, Qadir M, \& Drechsel P (2012). Water Quality: Assessment of the Current Situation in Asia. Int J Water Reso Dev. 28:195-216 .

5. Munns R, \& Tester M (2008). Mechanisms of salinity tolerance. Annual Review of Plant Biol. 59: 651-681.

6. Yadav S, Irfan M, Ahmad A, \& Hayat S (2011). Causes of salinity and plant manifestations to salt stress: a review. Journal of Environment bio. 32: 667-685.

7. Ramadoss D, Vithal KL, Pranita B, Sajad A, \& Kannepalli A (2013). Mitigation of salt stress in wheat seedlings by halotolerant bacteria isolated from saline habitats. Springer Plus. 2:6 doi:10.1186/2193-18012-6

8. Brady NC, \& Weil RR (2008). The Nature and Property of Soils, fourteenth ed. Pearson Prentice Hall, Upper Saddle River, NJ.
9. Hamdia MA, \& Shaddad MAK (2010). Salt tolerance of crop plants. Journal of Stress Physio. \& Biochem. 3: 64-90.

10. Mohamed HI, \& Gomaa EZ (2012). Effect of plant growth promoting Bacillus subtilis and Pseudomonas fluorescens on growth and pigment composition of radish plants (Raphanus sativus) under $\mathrm{NaCl}$ stress. Photosynthetica. 50 (2): 263-272.

11. Han HS, \& Lee KD (2005). Physiological responses of soybean - inoculation of bradyrhizobium japonicum with PGPR in saline soil conditions. Res $\mathbf{J}$ of Agri and Bioll Sci. 1(3): 216-221, 2005.

12. Egamberdieva D, \& Kucharova Z. (2009). Selection for root colonizing bacteria stimulating wheat growth in saline soils. Biology and Fertility of Soils. 45: 563-571.

13. Rabie GH, \& Almadini AM (2005). Role of bioinoculants in development of salt tolerance of Vicia faba plants under salinity stress. Afr. J. Biotechnol. 4: 210-222.

14. Del R, Corpas FJ, Sandalio LM, Palma JM, \& Barroso JB (2003). Plant peroxisomes, reactive oxygen metabolism and nitric oxide. IUBMB Life, 55: 71-81.

15. Jorquera MA, Hernández MT, Rengel Z, Marschner P, \& Mora ML (2008). Isolation of culturable phosphobacteria with both phytate-mineralization and phosphatesolubilization activity from the rhizosphere of plants grown in a volcanic soil. Biology and Fertility of Soils 44:1025-1034.

16. Creus CM, Sueldo RJ, \& Barassi CA (2004). Water relations and yield in Azospirilluminoculated wheat exposed to drought in the field. Canadian Journal of Bot. 82: 273-281.

17. Aroca R, Ferrante A, Vernieri P, \& Chrispeels MJ (2006). Drought, abscisic acid and transpiration rate effects on the regulation of PIP aquaporin gene expression and abundance in Phaseolus vulgaris plants. Annals of Bot. 98: 1301-1310.

18. Aroca R, Porcel R, \& Ruiz-Lozano JM (2007). How does arbuscular mycorrhizal symbiosis regulate root hydraulic properties 
and plasma membrane aquaporins in Phaseolus vulgaris under drought, cold or salinity stresses? New Phytol. 173: 808-816.

19. Marulanda A, Azco R, Chaumont F, RuizLozano JM, \& Aroca R (2010). Regulation of plasma membrane aquaporins by inoculation with a Bacillus megaterium strain in maize (Zea mays L.) plants under unstressed and salt-stressed conditions. Planta. 232: 533-543.

20. Choudhary DK, Sharma KP, \& Gaur RK (2011). Biotechnological perspectives of microbes in agro-ecosystems. Biotechnology Letters. 33: 1905-1910.

21. Bharti N, Yadav D, Barnawal D, Maji D, \& Kalra A (2013). Exiguobacterium oxidotolerans, a halotolerant plant growth promoting rhizobacteria, improves yield and content of secondary metabolites in Bacopa monnieri (L.) Pennell under primary and secondary salt stress. World J Microbiol Biotechnol. 29:379-387.

22. Chen M, Wei H, Cao J, Liu R, Wang Y, \& Zheng C (2007). Expression of Bacillus subtilis proAB genes and reduction of feedback inhibition of proline synthesis increases proline production and confers osmotolerance in transgenic Arabidopsis. Journal of Biochem and Mol Bio. 40:396403.

23. Kidoglu F, Gül A, Ozaktan H, \& Tüzel Y (2008). Effect of rhizobacteria on plant growth of different vegetables. Acta Hortic. 801:1471-1477.

24. Ocon A, Hampp R, \& Requena N (2007). Trehalose turnover during abiotic stress in arbuscular mycorrhizal fungi. New Phytol. 174: 879-891.

25. Figueiredo MVB, Burity HA, Martinez CR, \& Chanway CP (2008). Alleviation of drought stress in common bean (Phaseolus vulgaris L.) by co-inoculation with Paenibacillus polymyxa and Rhizobium tropici. Applied Soil Eco. 40: 182-188.

26. Perez-Alfocea F, Albacete A, Ghanem ME, $\&$ Dodd IC (2010). Hormonal regulation of source-sink relations to maintain crop productivity under salinity: a case study of root-to-shoot signalling in tomato. Functional Plant Bio. 37: 592-603.

27. Yang J, Kloepper JW, \& Ryu CM (2009). Rhizosphere bacteria help plants tolerate abiotic stress. Trends in Plant Sci. 14: 1-4.

28. Sannazzaro AI, Ruiz OA, Alberto EO, \& Mene' ndez AB (2006). Alleviation of salt stress in Lotus glaber by Glomus intraradices. Plant and Soil. 285: 279-287.

29. Kaya C, Ashraf M, Sonmez O, Aydemir S, Tuna AL, \& Cullu MA (2009). The influence of arbuscular mycorrhizal colonisation on key growth parameters and fruit yield of pepper plants grown at high salinity. Scientia Horti. 121: 1-6.

30. Hammer EC, Nasr H, Pallon J, Olsson PA, \& Wallander H (2011). Elemental composition of arbuscular mycorrhizal fungi at high salinity. Mycorrhiza 21: 117-129.

31. Hohnjec N, Vieweg MF, Puhler A, Becker A, \& Kuster H (2005). Overlaps in the transcriptional profiles of Medicago truncatula roots inoculated with two different glomus fungi provide insights into the genetic program activated during arbuscular mycorrhiza. Plant Phys. 137: 1283-1301.

32. Nadeem SM, Zahir ZA, Naveed M, \& Arshad M (2009). Rhizobacteria containing ACC-deaminase confer salt tolerance in maize grown on salt-affected fields. Canadian Journal of Microbiol. 55: 13021309.

33. Zhang H, Kim MS, Sun Y, Dowd SE, Shi H, \& Pare PW (2008). Soil bacteria confer plant salt tolerance by tissue-specific regulation of the sodium transporter HKT1. Molecular Plant Microbe Interactions. 21: 737-744.

34. delAmor F, \& Cuadra-Crespo P (2012). Plant growth-promoting bacteria as a tool to improve salinity tolerance in sweet pepper. Functional Plant Bio. 39: 82-90. 
35. Spaepen S, \& Vanderleyden J (2011). Auxin and plant-microbe interactions. Cold Spring Harb. Perspect. Biol. http://dx.doi.org/ 10.1101/cshperspect.a001438.

36. Glick BR, 2012. Plant Growth-Promoting Bacteria: Mechanisms and Applications. Hindawi Publishing Corporation, Scientifica.

37. Santner A, Calderon-Villalobos LIA, \& Estelle M (2009). Plant hormones are versatile chemical regulators of plant growth. Nature Chem. Biol. 5: 301-307.

38. Zaidi A, Khan MS, Ahemad M, \& Oves M (2009). Plant growth promotion by phosphate solubilizing bacteria. Acta Microbiol. Immunol. Hung. 56: 263-284.

39. Spaepen S, Vanderleyden J, \& Remans R (2007). Indole- 3-acetic acid in microbial and microorganism-plant signaling. FEMS Microbiol. Rev. 31: 425-448.

40. Bhattacharyy PN \& Jha DK (2012). Plant growth-promoting rhizobacteria (PGPR): emergence in agriculture. World J. Microbiol. Biotechnol. 28: 1327-1350.

41. Albacete A, Ghanem ME, Martı'nez-Andu' jar C, Acosta M, Sa' nchez-Bravo J, Martı'nez V, Lutts S, Dodd IC \& Pe' rezAlfocea F (2008). Hormonal changes in relation to biomass partitioning and shoot growth impairment in salinised tomato (Solanum lycopersicum L.) plants. Journal of Exp. Bot. 59: 4119-4131.

42. Dodd IC, Zinovkina NY, Safronova VI, \& Belimov AA (2010). Rhizobacterial mediation of plant hormone status. Annals of Applied Bio. 157: 361-379.

43. Naz I, Bano A, \& Ul-Hassan T (2009). Isolation of phytohormones producing plant growth promoting rhizobacteria from weeds growing in Khewra salt range, Pakistan and their implication in providing salt tolerance to Glycine $\max$ L. African Journal of Biotech. 8: 5762-5768.

44. Yao LX, Wu ZS, Zheng YY, Kaleem I, \& Li C (2010). Growth promotion and protection against salt stress by Pseudomonas putida Rs-198 on cotton. European Journal of Soil Biol. 46: 49-54.

45. Arkhipova TN, Prinsen E, Veselov SU, Martinenko EV, Melentiev AI, \& Kudoyarova GR (2007). Cytokinin producing bacteria enhance plant growth in drying soil. Plant and Soil. 292: 305-315.

46. McKenzie RH, \& Roberts TL (1990). Soil and fertilizers phosphorus update. In: Proceedings of Alberta Soil Science Workshop Proceedings, Feb. 20-22, Edmonton, Alberta, 84-104p

47. Rajput L, Asma, Fathia M, \& Fauzia YH (2013). Salt-tolerant pgpr strain planococcus rifietoensis promotes the growth and yield of wheat (Triticum aestivum L.) Cultivated in saline soil. Pak. J. Bot. 45(6): 1955-1962.

48. Ilyas N, Bano A, Iqbal S, \& Raja NI (2012). Physiological, biochemical and molecular characterization of Azospirillum spp. isolated from maize under water stress. Pak. J. Bot.44: 71-80.

49. Yasmin S, Hafeez F, Schmid M, \& Hartmann A (2013). Plant beneficial rhizobacteria for sustainable increased yield of cotton with reduced level of chemical fertilizer. Pak. J. Bot. 45(2): 655-662, 2013.

50. Qureshi MA, Ahmad ZA, Akhtar N, Iqbal A, Mujeeb F, \& Shakir MA (2012). Role of phosphate solubilizing bacteria (PSB) in enhancing $\mathrm{P}$ Availability and promoting cotton growth. The Journal of Animal \& Plant Sci. 22(1): 204-210. 